\title{
LETTER
}

\section{Comments on paper by W. L. Raines, T. M. Flanders and P. K. KuRODA "Superheavy elements in nature?: Fissiogenic xenon in Sudbury, Ontario, norite"}

RAINES et al. (1978) claim that CCF-like xenon is observed in stepwise heatings of terrestrial samples, and that this effect can be explained as the mass fractionation of the xenon isotopes produced by the spontaneous fission of ${ }^{238} \mathrm{U}$. We wish to point out a few errors in RAINES et al. and to offer an alternative interpretation of the data.

RAINES et al. calculate the fissiogenic compositions by assuming that ${ }^{130} \mathrm{Xe}$ is purely atmospheric, so that the atmospheric component can be subtracted by the equation

$$
\begin{aligned}
& \left(\frac{{ }^{i} \mathrm{Xe}}{{ }^{132} \mathrm{Xe}}\right)_{\mathrm{F}}
\end{aligned}
$$



where $R$ represents the measured values, $A$ the atmospheric component, and $\mathrm{F}$ the fissiogenic component. Table 1 gives the fissiogenic compositions we calculate for the temperature steps listed in Table 2 of RAINES et al. (their examples of steps which exhibit CCF-like xenon), and for a few temperature steps with 'normal' fissiogenic xenon. Our values disagree with RAINES et al. for Samples (3) and (5), and in all cases they have greatly underestimated the errors. Inspection of our Table 1 reveals that only Sample (6) has a fissiogenic composition different from ${ }^{238} \mathrm{U}$ by more than $2 \sigma$ in the direction of CCF xenon. (Sample (7) is more than $2 \sigma$ from ${ }^{238} \mathrm{U}$ spontaneous fission, but is in the direction of ${ }^{235} \mathrm{U}$ neutron-induced fission.) Samples (1) through (6), however, do show a trend towards a CCF-like component.

We suggest that the atmospheric subtraction should be based on ${ }^{129} \mathrm{Xe}$ rather than ${ }^{130} \mathrm{Xe}$ because: (1) being more abundant, ${ }^{129} \mathrm{Xe}$ can be determined with better precision; and (2) ${ }^{130} \mathrm{Xe}$ might be produced by the ${ }^{139} \mathrm{Xe}(\mathrm{n}, \gamma){ }^{130} \mathrm{Xe}$ reaction. Even though only small amounts of ${ }^{129} \mathrm{Xe}$ are present, the large neutron absorption cross section coupled with the substantial neutron fluences indicated by the large amounts of fissiogenic xenon may allow for measurable production of ${ }^{130} \mathrm{Xe}$. Indeed all the anomalous samples in Table 1, except for Sample (5), have negative $\left({ }^{129} \mathrm{Xe} /{ }^{130} \mathrm{Xe}\right)_{\mathrm{F}}$ ratios, as expected for excesses at ${ }^{130} \mathrm{Xe}$.

The inferred fissiogenic compositions using ${ }^{129} \mathrm{Xe}$ as the measure of the atmospheric content are set out in Table 2. The Table 2 values, except for Sample (5), lie closer to the ${ }^{238} \mathrm{U}$ spontaneous fission compositions than the Table 1 values--the trend towards CCF xenon has disappeared. For example, the most anomalous sample in Table 1, Sample (6), now agrees with ${ }^{238} \mathrm{U}$ spontaneous fission very well. The only remaining anomalous fissiogenic composition in Table 2 is Sample (5). This sample, however, shows a slight excess of ${ }^{129} \mathrm{Xe}$ in Table 1 , and a negative ${ }^{130} \mathrm{Xe} /{ }^{132} \mathrm{Xe}$ ratio in Table 2, suggesting that ${ }^{130} \mathrm{Xe}$ is probably a better measure of the atmospheric content due to a slight excess of ${ }^{129} \mathrm{Xe}$.

We recognize that ${ }^{129} \mathrm{Xe}$ can be produced by ${ }^{238} \mathrm{U}$ spontaneous fission and ${ }^{235} \mathrm{U}$ neutroninduced fission, but for rocks with low uranium concentrations, excesses of ${ }^{130} \mathrm{Xe}$ may be more readily apparent than excesses of ${ }^{129} \mathrm{Xe}$. Excess ${ }^{130} \mathrm{Xe}$ is proportional to the uranium content because the neutron fluence is proportional to the uranium content (except in the case of chain reactions). But because the amount of ${ }^{235} \mathrm{U}$ neutron-induced fission (the major contributor to an observable excess of ${ }^{129} \mathrm{Xe}$ from uranium fission processes) is proportional to the neutron fluence times the uranium content, the amount of excess ${ }^{129} \mathrm{Xe}$ is roughly proportional to the uranium content squared. For the low uranium contents of these samples, excesses at ${ }^{130} \mathrm{Xe}$ may overshadow excesses at ${ }^{129} \mathrm{Xe}$. The predominance of negative ${ }^{129} \mathrm{Xe} /{ }^{132} \mathrm{Xe}$ ratios in Table 1 and positive ${ }^{130} \mathrm{Xe} /{ }^{132} \mathrm{Xe}$ ratios in Table 2 for the CCF-like candidates is consistent with such ${ }^{130} \mathrm{Xe}$ excesses. Sample (6) most strikingly illustrates this effect as the ${ }^{130} \mathrm{Xe}$ excess is significant at the $4 \sigma$ level. Production of ${ }^{130} \mathrm{Xe}$ from 


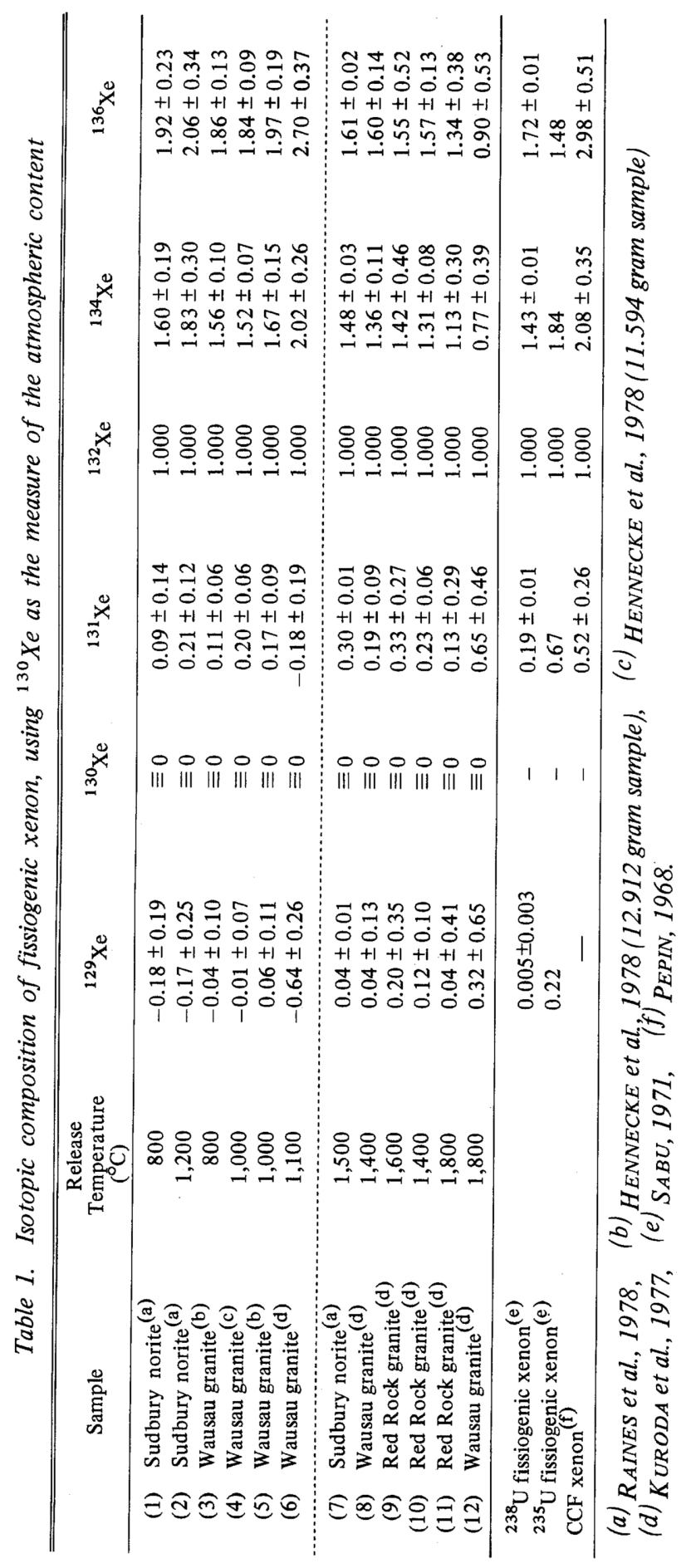

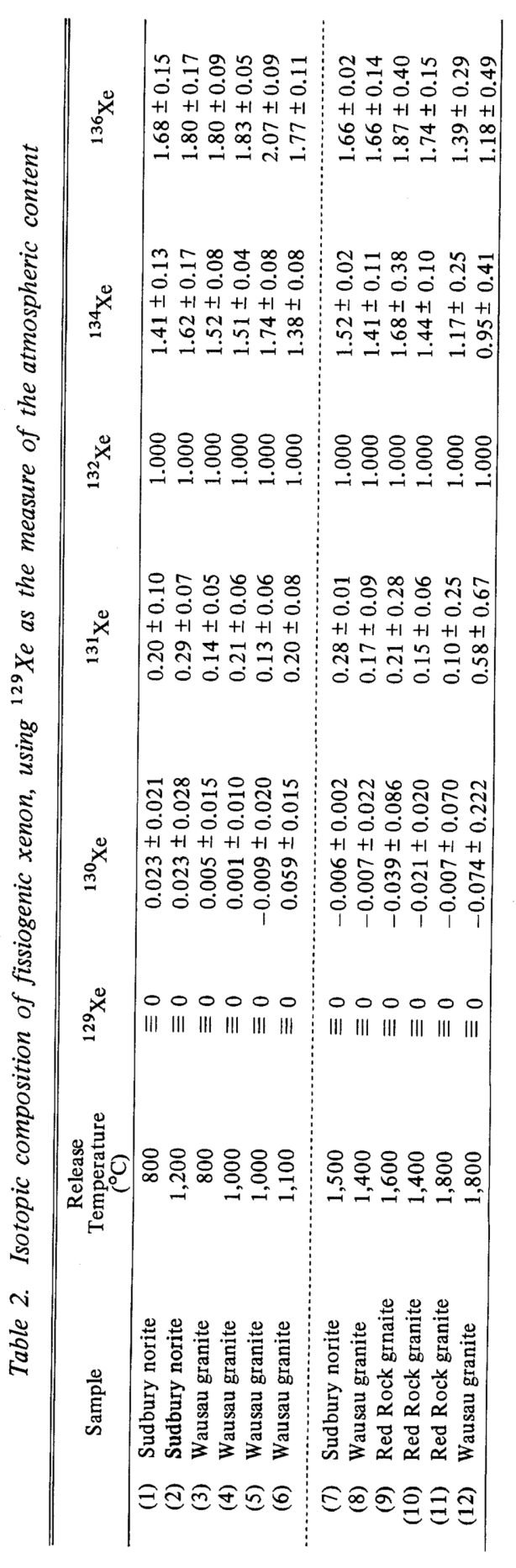


neutron capture has been reported by DROzD et al. (1974) for samples from the Oklo mine. We conclude that all the data are consistent with the presence of the following xenon components: .atmospheric xenon, ${ }^{238} \mathrm{U}$ spontaneous fission $x e n o n,{ }^{235} U$ neutron-induced fission xenon, and ${ }^{130} \mathrm{Xe}$ produced by neutron capture

Physics Department

University of California

Berkeley, CA 94720, U.S.A.

\section{REFERENCES}

Drozd, R. J., HohenberG, C. M. and Morgan, C. J. (1974) Heavy rare gases from Rabbit Lake (Canada) and the Oklo mine (Gabon): Natural spontaneous chain reactions in old uranium deposits. Earth Planet. Sci. Lett. 23, 28-33.

HENNECKE, E. W., B ALLARD, R. V. and MANUEL, O.K. (1978) Fission xenon in Wausau, Wisconsin granite. J. Inorg. Nucl. Chem. 40, 1281-1284.

Kuroda, P. K., SHERrill, R. D. and JACKSON, K. C. (1977) Abundances and isotopic compositions of rare gases in granites. Geochem. J. 11, 75-90. on ${ }^{129} \mathrm{Xe}$. The data do not support the claim for a fissiogenic component similar to $\mathrm{CCF}$ xenon in these samples. The implications of RAINES et al. regarding the origin of CCF xenon in meteorites are unwarranted on the basis of these data.

PEPIN, R. O. (1968) Neon and xenon in carbonaceous chondrites, in Origin and distribution of the elements, edited by L. H. AHRENS, Pergamon, New York, 379-386.

Raines, W. L., Flanders, T. M. and Kuroda, P. K. (1978) Superheavy elements in nature?: Fissiogenic xenon in Sudbury, Ontario, norite. Geochem. J. 12, 265-270.

SABU, D. D. (1971) On mass-yield of xenon and krypton isotopes in the spontaneous fission of uranium. J. Inorg. Nucl. Chem. 33, 1509-1513. 